\title{
Ketamine anaesthesia for medical procedures in children
}

\author{
ELIZABETH ELLIOTT, $\star$ T. K. HANID,† L. J. H. ARTHUR, and BRIAN KAY \\ From Derbyshire Children's Hospital, Derby
}

\begin{abstract}
Elliott, E., Hanid, T. K., Arthur, L. J. H., and Kay, B. (1976). Archives of Disease in Childhood, 51, 56. Ketamine anaesthesia for medical procedures in children. Ketamine hydrochloride $2 \mathrm{mg} / \mathrm{kg}$, together with atropine $0.2 \mathrm{mg}$, has been given intravenously on 100 occasions on a general paediatric ward. No serious side effects occurred. Dreams followed in 4 children but did not reduce acceptability of the drug. In our hands it has greatly reduced the pain and distress of children undergoing many routine medical procedures, particularly the dread which builds up when these have to be repeated in the same child. It has also produced close to ideal conditions for the operator, and probably increased his efficiency by reducing the emotional strain which occurs when doing painful things to a frightened patient.
\end{abstract}

In paediatric hospital practice today it is sometimes necessary to carry out investigations and treatment which may be both painful and frightening to the child. With children it is not only pain but the fear of pain which is damaging. Hitherto, local anaesthesia (freezing with ethyl chloride, or infiltration with lignocaine) or sedation with hypnotics, or lytic cocktails (for instance, promethazine, chlorpromazine, and pethidine) have been widely used. Neither of these methods is reliably effective; the child may either be awake and struggling during the procedure, or conversely, may remain asleep for many hours after. The formality of a traditional general anaesthetic is not practicable for lumbar punctures, marrow examination, or pleural aspiration. What is required is a safe, effective, and short-acting drug. Ketamine hydrochloride seems to fulfil these criteria. It was first synthesized in 1961 and clinical trials begun in 1964 (Domino, Chodoff and Corssen, 1965). It belongs to the phencyclidine group of drugs and can be given either intravenously or intramuscularly

The classical general anaesthetic affects consciousness by depressing the reticular activating system in the brain. Ketamine temporily converts the patient into a catatonic schizophrenic (Hunter, 1973). The parts of the brain concerned

Received 8 April 1975.

Present addresses: ${ }^{\star D}$ Darlington Memorial Hospital, Co. Durham. tSt. Mary's Hospital, London. with thinking, feeling, and moving are inhibited; other parts are unaffected. During induction the patient feels dissociated from his environment, and even from his own extremities. Analgesia and amnesia are conspicuous, but muscle relaxation is poor (Corssen and Domino, 1966). Corssen (Domino et al., 1965) has called this dissociative anaesthesia.

\section{Safety}

In ketamine anaesthesia there is little effect on the respiration; the gag and coughing reflexes are well preserved. However, Taylor and Towey (1971) reported a minor degree of inhalation in normal subjects under ketamine anaesthesia.

When ketamine is given intravenously, anaesthesia occurs within one minute and lasts up to half an hour. Blood pressure, heart rate, and cardiac output rise (Bovill et al., 1971; Tweed, Minuck, and Mymin, 1971; Savege et al., 1973). Involuntary movements are often seen. Salivation is increased and we have used atropine routinely for this reason. Transient skin rashes may occur. The most prominent side effect is dreaming, which is reduced if the patient is left quiet and undisturbed during recovery. Hallucinations, sometimes frightening ones (Coppel, Bovill, and Dundee, 1973), have been experienced by some adults but have not been a problem in children. Brief convulsions or twitching have been reported once or twice in every hundred or so administrations in children (Wilson, Nichols, and McCoy, 1967, Corssen et al., 1969a, b; Page, Morgan, and Loh, 1972), a more alarming convulsion in a woman of 26 (Thompson, 1972), and extensor spasms, with 
opisthotonos in two infants of 2 and 6 months by Radnay and Badola (1973).

Contraindications are few though they include hypertension (diastolic more than $100 \mathrm{mmHg}$ ), heart failure, raised intracranial pressure, and patients on thyroid medication. Ketamine is best avoided in the first year of life.

\section{Method}

Ketamine is a powerful drug and can occasionally produce respiratory depression, apnoea, or laryngeal spasm. We have limited its use to two pairs of skilled and readily available hands, such as those of the paediatric registrar. Facilities for intubation and assisted respiration must be available at the bedside, together with suction apparatus and oxygen. An anaesthetist should be present when the drug is being used for the first two or three occasions by an inexperienced operator.

Ketamine anaesthesia should be a formal procedure, and each administration should be recorded in a book specially kept for the purpose, together with indications, dosage, and any side effects noticed. A warning notice with a list of contraindications and the names of the authorized users may be affixed inside the cover. It is preferable that nothing should be taken by mouth for at least 3 hours before administration of ketamine, though vomiting is rare. Only in an extreme emergency should it be given without starvation (Phillips et al., 1970).

We used ketamine hydrochloride $2 \mathrm{mg} / \mathrm{kg}$, given slowly intravenously, together with atropine $0.2-0.3 \mathrm{mg}$ through the same needle. No premedication was given. If the procedure was prolonged and the child showed signs of waking, then a further 5-10 mg ketamine were given. After the procedure was completed, the child was placed lying on his side and left undisturbed under close supervision until awake.

\section{Results}

100 administrations of ketamine were given to 61 children for a total of 110 procedures (Table I).

\section{TABLE I}

Ketamine anaesthesia on a paediatric ward

Total no. of administrations of ketamine

Total no. of children given ketamine

Total no. of procedures

Note: Some children had more than one procedure carried out under the same injection of ketamine, and some had repeated administrations of ketamine on different days.

The children's ages ranged from 17 months to $13 \frac{1}{2}$ years. One 13-year-old girl who was given ketamine on 11 occasions consistently required 10 mg more than the calculated dose for effective anaesthesia. Satisfactory anaesthesia was achieved on all 100 occasions. No child required intubation or oxygen. Details of the procedures are given in Table II.
TABLE II

\section{Medical procedures undertaken using ketamine}

\begin{tabular}{lr}
\hline Lumbar puncture & 73 \\
Bone marrow aspiration & 15 \\
Chest aspiration or chest drain insertion & 7 \\
Pericardial aspiration & 5 \\
Skin dressings & 2 \\
Other procedures & 8 \\
\hline Total & 110 \\
\hline
\end{tabular}

\section{TABLE III}

\section{Complications in 100 administrations of ketamine}

Vomiting

Diastolic blood pressure 90 or above

Convulsions

Total

Note: 4 children admitted to dreams on direct questioning, but these were never alarming or frightening.

Complications, none serious, are recorded in Table III. Vomiting occurred in the recovery phase in 3 children. Strange dreams, possibly amounting to hallucinations, occurred in 4 children, one of whom (the 13-year-old previously mentioned) had dreams on each of the 11 administrations. This did not appear to upset her, or any of the other affected children. Hypertension, defined as a diastolic blood pressure of more than $90 \mathrm{mmHg}$, was found on 6 occasions, and diastolic pressure greater than $100 \mathrm{mmHg}$ twice.

Two brief convulsions lasting 3 seconds each were seen in a child with idiopathic thrombocytopenic purpura during a bone marrow aspiration. He had no previous history of convulsions and they did not recur during a 6-month follow-up period. Ketamine has been claimed to have some anticonvulsant activity (Corssen et al., 1969b), but several other authors have reported convulsions (Wilson et al., 1967; Page et al., 1972; Thompson, 1972; Radnay and Badola, 1973).

Cerebrospinal fluid pressure readings will also be affected, but are still probably less so than in a crying, struggling child without anaesthesia.

\section{Discussion}

Reports have been published on the use of ketamine in specialized situations with children, for example with burns (Wilson et al., 1967), cardiac catheterization (Stanley et al., 1968; Faithfull and Haider, 1971), neuroradiology (Corssen et al., 1969b), radiotherapy (Page et al., 1972), and out- 
patient surgical procedures (Ahlgren, Bennett, and Stephen, 1971).

We are unaware of reports of its routine use for painful medical procedures on a general children's ward, though it has been widely used for repeated bone marrow and lumbar punctures in leukaemic children (Matthias and Knapton, 1972; Keilty and Bridges, 1972; Meadows, Mayer, and Naiman, 1972).

Articles written by anaesthetists suggest that ketamine anaesthesia 'requires the presence of a skilled anaesthetist as much as any other form of general anaesthesia' (Page et al., 1972) but in our small series we have shown it to be safe and effective in less specialized hands. As recovery is rapid after ketamine anaesthesia, it can be given to day patients. Ketamine is nevertheless a potentially dangerous drug and should be given by doctors who are aware of the dangers and are able to give positive pressure ventilation if the need should arise.

A quiet child feeling no pain, breathing normally, and able to cough, greatly reduces the stress on the operator in carrying out painful procedures and is likely to increase his success rate. It seems likely that the hallucinogenic side effects are less serious in children than in adults. Though Boyd, Barry, and Davis (1971) for instance warn that children especially over the age of 6 may have unpleasant dreams about which they do not complain spontaneously, our 13-year-old who dreamt consistently whenever she had ketamine displayed no apprehension or unwillingness to repeat the experience.

Hypertension appears to be mainly a theoretical disadvantage in children, but patients who are being treated with thyroxine may develop alarming increases in blood pressure and pulse rate after ketamine (Kaplan and Cooperman, 1971).

The possibility of more sinister long-term effects on the brain due to excitation of deeper structures in the central nervous system has been raised by Winters in an editorial (1972). It is based on animal work (Mori et al., 1971; Kayama and Iwama, 1972), but studies with implanted electrodes in man (Ferrer-Allado et al., 1973) have confirmed the appearance of paroxysmal disturbances in the limbic and thalamic regions analogous to those produced by dangerous hallucinogens such as mescaline. It would be fair to say that these warnings are more relevant to the high and prolonged doses of ketamine that may be used in general anaesthesia for surgical procedures. However, misleading results may be obtained on an EEG if the recording is made within 2 or 3 days of administration of ketamine.

Ketamine is effective intramuscularly but the onset of the anaesthesia is slower, the recovery longer, the injection is painful (most children strongly resent the intramuscular injection, ApIvor, 1973), and the dosage levels higher by a factor of 5 or 6 times, e.g. $12 \mathrm{mg} / \mathrm{kg}$. In view of Winter's strictures on this class of anaesthetic, the minimal effective dose is the safest, particularly when it is used for minor procedures.

We thank Dr. M. W. Moncrieff who allowed us to use ketamine on his patients, and the sisters and nursing staff of Ward 4 for their co-operation.

\section{REFERENCES}

Ahlgren, E. W., Bennett, E. J., and Stephen, C. R. (1971). Outpatient pediatric anesthesiology. A case series. Anesthesia and Analgesia Current Researches, 50, 402.

ApIvor, D. (1973). Ketamine in paediatric ophthalmic surgery. Anaesthesia, 28, 501.

Bovill, J. G., Clarke, R. S. J., Davis, E. A., and Dundee, J. W. (1971). Some cardiovascular effects of ketamine in man. British fournal of Pharmacology, 41, 411 .

Boyd, N. A., Barry, N. A., and Davis, A. K. (1971), British surgical aid to Jordan. Annals of the Royal College of Surgeons of England, 49, 291.

Coppel, D. L., Bovill, J. G., and Dundee, J. W. (1973). The taming of ketamine. Anaesthesia, 28, 293.

Corssen, G., and Domino, E. F. (1966). Dissociative anesthesia; further pharmacologic studies and first clinical experience with phencyclidine derivative CL-581. Anesthesia and Analgesia Current Researches, 45, 29.

Corssen, G., Domino, E. F., and Bree, R. L. (1969a). Electroencephalographic effects of ketamine anesthesia in children. Anesthesia and Analgesia Current Researches, 48, 141.

Corssen, G., Groves, E. H., Gomez, S., and Allen, R. J. (1969b). Ketamine: its place in anesthesia for neurosurgical diagnostic procedures. Anesthesia and Analgesia Current Researches, 48, 181.

Domino, E. F., Chodoff, P., and Corssen, G. (1965). Pharmacologic effects of CL-581. A new dissociative anesthetic in man. Clinical Pharmacology and Therapeutics, 6, 279.

Faithfull, N. S., and Haider, R. (1971). Ketamine for cardiac catheterisation. An evaluation of its use in children. Anaesthesia, 26, 318.

Ferrer-Allado, T., Brechner, V. L., Dymond, A., Cozen, H., and Crandall, P. (1973). Ketamine-induced electro-convulsive phenomena in human limbic and thalamic regions. Anesthesiology, 38, 333.

Hunter, A. R. (1973). Drugs for producing dissociative states. Recent Advances in Anaesthesia and Analgesia, 11th ed., p. 1. Ed. by C. L. Hewer. Churchill Livingstone, Edinburgh and London.

Kaplan, J. A., and Cooperman, L. H. (1972). Alarming reactions to ketamine in patients taking thyroid medication. Treatment to ketamine in patients taking thyroid medica
with propranolol. Anesthesiology, 35, 229.

Kayama, Y., and Iwama, K. (1972). The E.E.G., evoked potentials and single unit activity during ketamine anesthesia in cats. Anesthesiology, 36, 316.

Keilty, S. R., and Bridges, J. M. (1972). Ketamine for minor procedures in children. Lancet, 1. 631.

Matthias, J. Q., and Knapton, P. J. (1972). Ketamine for minor procedures in children. Lancet, $1,388$.

Meadows, A. T., Mayer, B. W., and Naiman, J. L. (1972). Ketamine for minor procedures in children. Lancet, 1,631 .

Mori, K., Kawamata, M., Mitani, H., Yamazaki, V., and Fujita, M. (1971). A neurophysiologic study of ketamine anesthesia in the cat. Anesthesiology, 35, 373.

Page, P., Morgan, M., and Loh, L. (1972). Ketamine anaesthesia in paediatric procedures. Acta Anaesthesiologica Scandinavica, 16, 155. 
Phillips, L. A., Seruvata, S. G., Rika, P. N., and Tirikula, U. (1970). Anaesthesia for the surgeon-anaesthetist in difficult situations. Anaesthesia, 25, 36.

Radnay, P. A., and Badola, R. P. (1973). Generalized extensor spasms in infants following ketamine anesthesia. Anesthesio$\log y, 39,459$.

Savege, T. M., Blogg, C. E., Foley, E. I., Ross, L., Lang, M., and Simpson, B. R. (1973). The cardio-respiratory effects of althesin and ketamine-a comparison. Anaesthesia, 28, 391.

Stanley, V., Hunt, J., Willis, K. W., and Stephen, C. R. (1968). Cardiovascular and respiratory function with CL-581. Anesthesia and Analgesia Current Researches, 47, 760.

Taylor, P. A., and Towey, R. M. (1971). Depression of laryngeal reflexes during ketamine anaesthesia. British Medical fournal, 2,688 .
Thompson, G. B. (1972). Ketamine-induced convulsions. Anesthesiology, 37, 662.

Tweed, W. A., Minuck, M., and Mymin, D. (1971). Circulatory responses to ketamine anesthesia. Anesthesiology, 37, 613.

Wilson, R. D., Nichols, R. J., and McCoy, N. R. (1967). Dissociative anesthesia with CL-581 in burned children. Anesthesia and Analgesia Current Researches, 46, 719.

Winters, W. D. (1972). Epilepsy or anesthesia with ketamine. Anesthesiology, 36, 309.

Correspondence to Dr. L. J. H. Arthur, Derbyshire Children's Hospital, North St., Derby DE1 3BA. 